\title{
Enfermedades fictivas y ficticias en La guerra silenciosa de Manuel Scorza
}

Fictive and fictitious diseases in La guerra silenciosa, by Manuel Scorza

\author{
Ofelia Huamanchumo de la Cuba ${ }^{1}$ \\ Universidad de Múnich. Múnich, Alemania \\ ofelia.huamanchumo@romanistik.uni-muenchen.de \\ ORCID: 0000-0002-6874-4861
}

Citar como: Huamanchumo, O. (2019). Enfermedades fictivas y ficticias en La guerra silenciosa, de Manuel Scorza. Desde el Sur, 11(2), pp. 23-31.

\section{RESUMEN}

En el mundo narrado de las cinco novelas de La guerra silenciosa aparecen representadas ciertas circunstancias desfavorables a personajes principales, a grupos particulares, a comunidades enteras, a animales, e incluso también a entes geográficos, en el plano social, económico y geopolítico, como si fueran «enfermedades». Todas ellas (entre otras: mal de la invisibilidad, insomnio de siglos, epidemia de daltonismo, etc.) se pueden entender como enfermedades fictivas y agrupar en dos conjuntos para su análisis: a) enfermedades fictivas con correlato en la realidad, y b) enfermedades fictivas y ficticias (sin correlato en la realidad). En ese sentido, el objetivo principal de este artículo es describir dichos trastornos, afecciones y padecimientos desde el punto de vista de la medicina y de la teoría literaria, para perfilar las funciones narratológicas que cumplen dentro de la ficción scorziana, a saber: utilizar la ironía y el humor como recursos discursivos en una literatura de denuncia social.

1 Dr. Phil. en Filología Románica por la Ludwig-Maximilians-Universität (LMU) de Múnich (Alemania), donde es profesora adjunta del Instituto de Filología Románica (Sección Español). Magíster en Hispanística, Literatura Comparada y Literatura Alemana Contemporánea (LMU), y bachiller en Humanidades, con mención en Lingüística y Literatura (Pontificia Universidad Católica del Perú, PUCP). Es miembro asociado del Instituto Riva-Agüero (PUCP), así como miembro del Instituto de Estudios sobre España, Portugal y Latinoamérica de la Universidad de Augsburg (UniA) (Alemania), en la que también es profesora adjunta de la cátedra de Literatura Iberorrománica. Sus campos de interés son la literatura hispanoamericana contemporánea (temas: la gran urbe, violencia, teatro) y las clases y géneros textuales (discursos jurídico, eclesiástico, historiográfico y literario) en español de la Temprana Edad Moderna en España y América colonial. 


\section{PALABRAS CLAVE}

Humor, ironía, denuncia social, enfermedades fictivas, La guerra silenciosa

\section{ABSTRACT}

In the narrative world of the five novels in the series La guerra silenciosa, certain circumstances are depicted as unfavorable to the main characters, to particular groups, to entire communities, to animals, and even to geographical entities, on a social, economic and geopolitical level, as if they were 'diseases'. These include the illness of invisibility, centuries of insomnia, and an epidemic of color blindness, among others, and they can be understood as fictive diseases and grouped for analysis into two categories: (a) fictive diseases with a correlation to reality; (b) fictive and fictitious diseases without a correlation to reality. The main goal of this article is to describe these disorders, afflictions and ailments from the perspectives of medical science and literary theory, in order to outline the narratological functions they perform within Scorzian fiction, namely: the use of irony and humor as discursive resources within a literature of social denunciation.

\section{KEYWORDS}

Humor, irony, social denunciation, fictive diseases, $L a$ guerra silenciosa

\section{Introducción: Las «enfermedades» en el mundo de La gue- rra silenciosa}

La guerra silenciosa es el nombre con que la crítica literaria llamó al conjunto de cinco novelas del escritor Manuel Scorza publicadas en la década de 1970, cuyos temas principales giraban en torno a la situación relegada en la que vivían los pobladores de las zonas de la sierra central del Perú, a causa de los abusos cometidos por parte de una transnacional minera frente a la tenencia de tierras para el pastoreo y la agricultura, y otros derechos vulnerados a los campesinos y ganaderos nacionales. Se trata de las novelas Redoble por Rancas (1970), Historia de Garabombo, el Invisible (1972), El jinete insomne (1977), Cantar de Agapito Robles (1977) y La tumba del relámpago (1979), las cuales, a pesar de mantener independencia entre sí, constituyen a todas luces una saga y, por ende, todas pueden ser vistas como parte componente de un mismo mundo literario, a pesar de tratarse de cinco diégesis —en términos de Genette (1989)— distintas. 
En la trama que se da en ese mundo común de las cinco historias ocurren ciertos acaecimientos desfavorables a los héroes novelescos. No todas esas coyunturas negativas constituyen una «enfermedad», si se toma en cuenta este término en el sentido estricto de la palabra, es decir: a) «Alteración más o menos grave de la salud», según el Diccionario de la lengua española (RAE, 2019). No obstante, considerando las otras dos acepciones de la misma fuente, es decir, b) «Pasión dañosa o alteración en lo moral o espiritual» (2019), y c) «Anormalidad dañosa en el funcionamiento de una institución, colectividad, etc.» (2019), se comprende que Scorza haya presentado circunstancias negativas a los protagonistas, a grupos particulares, a comunidades enteras, a animales, a entes geográficos e incluso a objetos del mundo de La guerra silenciosa como «enfermedades».

Visto así, se puede hacer una reducción metodológica para analizar las enfermedades que existen en el mundo de La guerra silenciosa scorziana, es decir, las enfermedades fictivas, agrupándolas en dos conjuntos: a) enfermedades fictivas con correlato en la realidad, explicables ya sea por las ciencias médicas, o por las supersticiones o creencias del mundo andino; $y$ b) enfermedades fictivas y ficticias (falsas o inventadas en base a la fantasía del autor), sin correlato en la realidad. En ese sentido, el objetivo principal del presente artículo es perfilar las funciones narratológicas que cumplen los trastornos, las afecciones y los padecimientos presentados dentro de la ficción scorziana.

\section{Enfermedades fictivas con correlato en la realidad}

\subsection{Según las ciencias médicas y considerando los tipos de patología, en La guerra silenciosa aparecen las siguientes enfermedades:}

2.1.1. Una epidemia de daltonismo y un virus; ambos males se presentan en la saga relacionados entre sí. Según el Diccionario médico-biológico, histórico y etimológico de la Universidad de Salamanca (USal), se entiende por: a) «epidemia (Patol. general). Enfermedad que se propaga durante algún tiempo en una población y que afecta a gran número de personas» (USal, 2019); b) «virus (Patol. infecciosa). Germen patógeno; microorganismo que puede causar o propagar enfermedades; (Microbiol.). Organismo de estructura sencilla, compuesto de proteínas y ácidos nucleicos, y capaz de reproducirse solo en el seno de células vivas específicas, utilizando su metabolismo» (2019); y c) «daltonismo: (Patol. oftalmol.). Incapacidad genética para distinguir ciertos colores, especialmente la diferencia entre verde y rojo» (2019).

La representación fictiva de estas enfermedades en Redoble por Rancas es como sigue: 
Nunca se supo por qué una epidemia azotó Cerro de Pasco. Un desconocido virus infectó los ojos de los habitantes. Aparentemente las víctimas gozaban de la integridad de su visión, pero un novedoso daltonismo les escamoteaba algunos objetos. Un enfermo, por ejemplo, capaz de señalar las manchas de una oveja a un kilómetro, era incapaz de distinguir un cerco situado a cien metros. Hasta los enfermeros de la Unidad Sanitaria comprendieron que los visitaba un suceso sin precedentes en la medicina. [...] Por la epidemia fracasaron las gestiones del alcalde: nadie veía el cerco (Scorza, 1977a, pp. 186-187).

En este caso, las enfermedades mencionadas presentan de manera irónica, y hasta burlesca, una situación singular que da lugar a varias interpretaciones a nivel metafórico.

2.1.2. En cuanto a las patologías oftalmológicas —aparte del daltonismo ya mencionado-, aparecen otras dos como atributos extraordinarios de personajes principales de la saga scorziana: la ceguera y la nictalopía. Por ceguera se entiende: «Pérdida completa de la visión» (USal, 2019), que es la que sufre doña Añada. Esta característica tiene un carácter casi de oxímoron, ya que, siendo ciega doña Añada, tiene la capacidad de ver el futuro y lo va tejiendo en unos ponchos: «Así recibieron el primero de los ponchos que la gratitud de doña Añada tejería para la personería [...] Lo que todos suponían producto de los delirios de la ciega, era en verdad el futuro» (Scorza, 1977c, p. 119).

Por su parte, Héctor Chacón, un héroe que participa en toda la saga, sufre nictalopía, en el sentido moderno de la palabra. En su acepción original, la nictalopía aludía a la «(Patol. oftalmol.). Ceguera nocturna, por la que al llegar la noche se ve con dificultad (acepción original a partir del siglo XVIII)» (USal, 2019). Actualmente: «(Biol.). Dícese de una persona o especialmente de un animal: que ve mejor de noche que de día» (RAE, 2019); este último es el atributo que se le adjudica al Nictálope, Héctor Chacón, junto con la capacidad de lanzar unas carcajadas hiperbólicas (Scorza, 1977a, p. 62). Con ambas características la novela alcanza un carácter épico, pues reviste a su héroe de características extraordinarias. $A$ nivel narratológico, esa carcajada febril puede ser un elemento de prolepsis en la estructura discursiva de la novela².

2 Este elemento de la carcajada hiperbólica se repite en otras novelas de La guerra silenciosa como recurso narrativo (Huamanchumo, 2015, pp. 81-82) y simbólico (Huamanchumo, 2014 , p. 269), en respuesta a muchas situaciones, mientras que, como se ha mencionado, Héctor Chacón, el Nictálope, inicia la historia personal de su venganza en Redoble por Rancas con una carcajada estruendosa (Scorza, 1977a, p. 62), Garabombo, el Invisible lanza una carcajada escandalosa para abrir un suspenso especial en la historia (Scorza, 1972, p. 93-94), y en Cantar de Agapito Robles (Scorza, 1977c, pp. 233-234) Agapito se carcajea hacia el final de la novela frente a la llegada de la muerte. 
2.1.3. En la medicina general, el insomnio es considerado como: «(Patol. general). Dificultad para conciliar el sueño; la forma más frecuente es tener dificultad para iniciarlo, pero puede consistir en despertarse con frecuencia durante la noche o demasiado pronto en la mañana» (USal, 2019). El héroe de la historia en El jinete insomne padece de insomnio:

[Crisóstomo Crispín:] Hace semanas que no duerme, don Raymundo.

—iProtéjase, don Raymundo! Está usted enfermo.

[Raymundo Herrera:] No, no dormí... ¿Era 1881? [...] ¿Quién ordenó que mi edad se detuviera? [...] estoy parado sobre el suelo de todas las generaciones, detrás de esta queja. [...] Ciertas noches pienso: ¿Seré yo el único forzado a proseguir con los ojos abiertos? (Scorza, 1977b, pp. 163-165).

Se trata a todas luces de un insomnio de carácter hiperbólico. Siguiendo la noción de metáfora de la teoría literaria, el insomnio en El jinete insomne alcanza ribetes metafóricos, cumpliendo la función de comparar el sentido verdadero de la imposibilidad de conciliar el sueño con la injusticia que sufren esos pueblos relegados, que no descansa, se mantiene en vigilia y vigente.

2.1.4. Dos males, como una peste y un infarto, aparecen en calidad de misteriosos. Es el caso de la muerte inexplicable del ganado ovino a causa de una peste, hecho que, en feliz casualidad, deja el terreno libre para la compañía minera abusadora. Se entiende por peste: «(Patol. infecc.). Enfermedad infecciosa aguda causada por la bacteria Yersinia pestis, que afecta a los animales, en especial roedores, [...]. Llega al hombre por picadura de pulga y por vía aérea a partir de un enfermo de peste pulmonar. La enfermedad presenta tres formas, la más frecuente es la peste bubónica con tumefacción de los ganglios linfáticos (bubones); la forma septicémica es muy grave, de invasión sanguínea y evolución muy rápida, y la peste pulmonar con afectación de todo el pulmón, es muy contagiosa y se denomina la muerte negra por la intensa cianosis o coloración azulada de los enfermos terminales. Actualmente sigue presentándose en países africanos, asiáticos y de América del Sur» (USal, 2019). La presentación de este mal en Redoble por Rancas no resulta, sin embargo, ficticia ni metafórica; es una peste de grandes dimensiones:

La carretera a Cerro de Pasco era un collar de cien kilómetros de ovejas moribundas. Rebaños famélicos rascaban las últimas matas en las estrecheces que, a cada lado de la carretera, toleraba la imperiosidad del cerco [...] Imaginaron que era peste. La señora Tufina mandó comprar ungüento contra la gusanera. Su hija trajo además agua bendita. 
Ni el ungüento ni el agua bendita detuvieron la mortandad. Morían por millares. La carretera corría entre dos encías de baba blanca (Scorza, 1977a, p. 90).

El caso del infarto colectivo no se hace presente en el discurso del narrador, sino que un personaje utiliza en la historia de Redoble por Rancas dicho término para encubrir el asesinato de varios peones de la hacienda El Estribo a manos de su hacendado, quien pone esa justificación en un telegrama al Juez (Scorza, 1977a, p. 100). Si bien el infarto es: «(Patol. cardiovascular). La degeneración de un órgano o parte de él por falta de riego sanguíneo, debido a la obstrucción de la arteria correspondiente; o de un tejido por muerte de células (necrosis)» (USal, 2019), agregarle el carácter «masivo» -en asociación tal vez a la histeria colectiva, que sí existe en la realidad - es presentar en el mundo retratado de dicha novela a las autoridades oficiales, aprovechándose de la ignorancia y la impotencia de los familiares de los campesinos muertos. En este caso no se trata de representar una enfermedad ficticia, sino de mostrar un acto de corrupción de alguien que utiliza su poder en beneficio propio.

2.1.5. Por último, se presenta la enfermedad de la parálisis. Según el DMBHE, se entiende por parálisis: «(Patol. general). Privación o disminución del movimiento de una o varias partes del cuerpo» (USal, 2019). En la saga la padecen accidentes geográficos y hasta objetos. En El jinete insomne el río Chaupihuaranga queda convertido en lago; de igual modo, el tiempo (Scorza, 1977b, p. 87, pp. 101-103, p. 151-158; 1977c, pp. 107-108) y los relojes (Scorza, 1977b, pp. 32-38) se enferman y detienen. Todo ello como metáfora de la paralización del desarrollo de Cerro de Pasco, ya que en la realidad ni ríos, ni nubes, ni mucho menos relojes pueden contraer enfermedades. Nuevamente males, como una parálisis adquieren una función metafórica o simbólica.

\subsection{Enfermedades fictivas con correlato en la realidad según supersticiones y creencias}

2.2.1. Mal de ojo: «Es una enfermedad originada por la «mirada fuerte» de algunos individuos, ya sea por envidia o determinados estados de ánimo sufridos por esa persona. Los niños son los más afectados, pero las plantas y animales [también pueden sufrir] por este mal. Es una de las creencias más antiguas y difundidas a nivel mundial. Entre los síntomas más frecuentes están el vómito, la diarrea, el llanto, la intranquilidad, entre otros (Ochoa y Quito, 2016, p. 18). En La guerra silenciosa las almas pueden producir mal de ojo: «Y es que don Migdonio temía el mal de ojo. Ese gigante que no se abatía ante ningún humano tiritaba bajo su frazada cada vez que los perros aullaban al paso de las ánimas» (Scorza 1977a, p. 99). 
2.2.2. Susto o espanto: «Se atribuye a la «pérdida del ánima», entendida como la falta de una entidad anímica localizada en la cabeza; esto sucede de manera sobrenatural, hecho dado por algunos «aires», desencadenando una reacción temerosa ante circunstancias imprevistas. Los síntomas físicos son agitación, insomnio, náusea, vómito, cefalea; se pueden acompañar con apatía, depresión, introversión, cuadros delirantes, alucinatorios y confusionales» (Ochoa y Quito, 2016, p. 17). En Historia de Garabombo, el Invisible: «iGarabombo asustó al personero Sánchez! ¿Le han visto las orejas transparentes? ¡Es susto!» (Scorza, 1972, p. 169).

\section{Enfermedades ficticias, por ser imposibles de darse en la realidad}

a. Los miembros de una comunidad adoptan diversos colores faciales (Scorza 1977a, p. 105; 1977b, pp. 213-215).

b. Garabombo (Scorza, 1972, pp. 11-13, p. 25, p. 31) y las quejas, abusos y reclamos a las autoridades sufren invisibilidad (1972, p. 209). En el caso de este héroe se trata también de una característica hiperbólica, algo típico del discurso épico.

c. Un grupo de vecinos sufren el mal de responder con un «sí» a todo: «Gastaron media mañana interrogando a los vecinos, pero aparentemente todos padecían idéntica psitácosis. Todas las preguntas desembocaban en la misma exasperante afirmativa» (Scorza, 1972, p. 185). La enfermedad existe: se trata de una infección que ataca a loros y papagayos, y puede transmitirse a los humanos.

d. Las manos de Nuño florecen y hacen florecer todo lo que tocan (1977c, p. 81).

e. Un caballo toma un color verde (1977c, p. 175).

f. Existe una enfermedad que hace brillar a los hombres (1987, pp. 7879).

g. Un enfermo mental jorobado sufre metamorfosis al transformarse en una persona cuerda y hermosa (1977b, p. 152) y al retornar a su estado original (1977b, pp. 232-233). Aquí la metamorfosis, que en zoología se entiende como el «cambio que experimentan muchos animales durante su desarrollo, y que se manifiesta no solo en la variación de forma, sino también en las funciones y en el género de vida» (RAE, 2019), en la novela es presentada como un mal de la salud de un personaje que sufre transformaciones. En este caso se trata claramente de una enfermedad ficticia.

En todas estas enfermedades ficticias la función que cumple su presentación fantástica puede que sea ideológica, ya que los elementos fantásticos del discurso scorziano construyen un sistema de signos 
encubiertos que organizan versiones simbólicas del nivel empírico cotidiano (Moraña, 1983, p. 191).

\section{Comentario final}

Luego de describir las enfermedades de La guerra silenciosa desde la medicina y considerando las nociones de teoría literaria, se puede perfilar la función que cumplen dichas presentaciones tanto de manera ficticia, o no, en la ficción scorziana. Para ello, hay que tener en cuenta una pieza clave en la lectura de La guerra silenciosa. Al inicio de la primera novela se le dice al lector, a través de una «noticia fictiva», que se tratará de una crónica exasperantemente real para ubicarlo en una estética realista (González, 1999, p. 148). Además, se advierte que «los protagonistas, los crímenes, la traición y la grandeza casi tienen aquí sus nombres verdaderos» (Scorza 1977a, p. 9) y «los excesos de este libro son desvaídas descripciones de la realidad» (p. 9). Se agrega que «ciertos hechos y su ubicación geográfica, ciertos nombres, han sido excepcionalmente modificados» (p. 10). En otras palabras, se advierte desde el comienzo que habrá una serie de excesos, es decir, un tipo de hechos exagerados (como que alguien sufra invisibilidad, o que exista un insomnio de siglos o una epidemia de daltonismo). Finalmente, pese a que se explicita que se tratará de un producto de la fantasía del autor, él mismo lo justifica en la medida en que le propone al lector un juego que parte de una propuesta irónica: «Para proteger a los justos de la justicia» (Scorza 1977a, p. 10). Con esto se ve que la función principal al presentar modificaciones en el carácter de las enfermedades ha cumplido el rol de utilizar metáforas, hipérboles e imaginación, sobre todo para ironizar el discurso, que tiene la peculiaridad de usar el humor para denunciar. Y todo ello quizás porque para Manuel Scorza la victoria contra sociedades tan primitivas, tan injustas, tan crueles - lo dijo en una entrevista-, era vivir, amar, escribir, reír. Sobre todo, reír (Scorza, 1981, p. 107).

\section{Contribuciones}

Ofelia Huamanchumo de la Cuba ha participado en la concepción del artículo, la recolección de datos, su redacción y aprobación de la versión final.

\section{Fuente de financiamiento}

Autofinanciado.

\section{Conflictos de interés}

La autora declara no tener conflictos de interés. 


\section{REFERENCIAS BIBLIOGRÁFICAS}

USal (2019). Diccionario médico-biológico, histórico y etimológico. Salamanca: Ediciones Universidad de Salamanca. Recuperado de https://dicciomed.usal.es/

Genette, G. (1989). Figuras III. Capellades: Romanyá Valls.

González Soto, J. (1999). La guerra silenciosa: Función del mito y la confluencia entre crónica y ficción. Socialismo y Participación (85), pp. 147-156.

Huamanchumo de la Cuba, O. (2015). Magia y fantasía en la obra de Manuel Scorza. Hacia una reflexión estructural de La guerra silenciosa. Berlín: E-Publi.

Huamanchumo de la Cuba, O. (2014). Protesta social en el discurso simbólico de La guerra silenciosa de Manuel Scorza. En E. Huarag (Ed.), Violencia social y política en la narrativa peruana (pp. 249-272). Lima: Instituto RivaAgüero y Pontificia Universidad Católica del Perú.

Moraña, M. (1983). Función ideológica de la fantasía en las novelas de Manuel Scorza. Revista de Crítica Literaria Latinoamericana, IX(17), pp. 171192.

Ochoa Murillo, J. F. y Quito Encalada, E. B. (2016). Patología andina relacionada al uso de plantas medicinales en los mercados 10 de Agosto, El Arenal y 9 de Octubre de la ciudad de Cuenca (2015) (tesis de Medicina). Universidad de Cuenca, Cuenta. Recuperado de https://dspace.ucuenca.edu.ec/ bistream/123456789/25099/1/Tesis.pdf

RAE (2019). Diccionario de la lengua española. Recuperado de https://dle. rae.es

Scorza, M. (1972). Historia de Garabombo, el Invisible. Barcelona: Planeta.

Scorza, M. (1977a). Redoble por Rancas. Caracas: Monte Avila Editores.

Scorza, M. (1977b). El jinete insomne. Caracas: Monte Avila Editores.

Scorza, M. (1977c). Cantar de Agapito Robles. Caracas: Monte Avila Editores.

Scorza, M. (1981). ¿Por qué no vivo en el Perú. (Encuesta). Hueso Húmero, 9, pp. 94-107.

Scorza, M. (1987). La tumba del relámpago. Lima: Peisa.

Recibido: 21/9/2019

Aceptado: 2/11/2019 